\title{
6. Teaching journalism in Oman: Reflections after the Arab Spring
}

\section{ABBSIHACI}

Between 2005-2011, the New Zealand Tertiary Education Consortium (NZTEC) was contracted to the Ministry of Higher Education (MOHE) in the Sultanate of Oman. This long-term, long-distance off-shore education contract committed four New Zealand universities to providing degrees in four discipline areas (as well as English language support) within the Omani Colleges of Applied Science. As part of this process, AUT University's Bachelor of Communication Studies was redeveloped for delivery in Oman. This case study will focus on the Journalism major and in particular the nature of the courses within this major, the difficulties encountered in redeveloping them and the challenge of delivering them under these particular circumstances in this particular time frame. The wider picture of the type of journalism practised in Oman; what is expected of - or indeed possible for- journalists in that society; and journalism as a force for democracy in Arab countries will also be briefly discussed.

Keywords: journalism education, Oman, higher education, cultural, sensitivity, contextualisation

SUSAN O'ROURKE

AUT University, Auckland

7 SULTANATE of Oman is located in the Arabian Gulf Cooperation Council area and Oman is bordered by Abu Dhabi, Dubai

1 and Fujairah to the north, Yemen to the south, Saudi Arabia to the west and the Arabian Sea, the Gulf of Oman and the Persian Gulf to the east. According to the CIA World Factbook estimate (July 2011), the population is 3,027, 959, including an extensive expatriate community from both Arab and Western countries. As visitors to Oman are regularly told, during the reign (1932-1970) of the previous Sultan Said bin Taimur A1 $\mathrm{Bu}$ Saidi, there were three primary schools and one hospital in the entire 
country; six miles of paved highway; watches and spectacles were not permitted; and the gates of the capital city, Muscat, were locked at night with a curfew imposed (al Bandary, 2005). The present Sultan Qaboos ibn Said replaced his father in 1970 and has presided over a rapid modernisation of the country based on oil wealth. The Cultural office of the Embassy of Oman in Washington, DC (2011) states that there are now over 1000 schools (90 percent of them government-run) including 132 private schools, one public university and plans for private universities in Nizwa and Salalah, alongside a series of public and private colleges (14) of different types including a technical college which has an accreditation scheme with a US institution. There are 57 hospitals including 9 private hospitals and 173 medical centres throughout the country (World Health Organisation, 2011). Nowadays not only are watches and spectacles permitted, they are often Rolexes and Ray-Bans, especially in Muscat. Muscat is a thriving capital city with a population of 634000 where cell phones are ubiquitous, and a rapidly expanding tourism sector comes complete with a vibrant nightlife.

\section{Background}

As well as growing numbers of tourists, Oman has a somewhat unusual (to some Western eyes) population spread with 60 percent of the population being under 18 and the median age of the population being 24.1 (CIA World Factbook, 2011). It also has a large population of expatriates and the Omani government has been searching for ways to reduce expatriate numbers and to provide more opportunities for its own people, particularly the young. As one senior member of the Ministry of Higher Education (MOHE) stated in 2006, the government is very aware of providing education for its young people and is making plans for the country in what was defined as the 'postpetrol' era. This has led to an ongoing Omanisation project which included, for example, training Omani teachers in six Colleges of Education in the various regions of the country. Once the government felt that an appropriate and sustainable number of Omani teachers was available, the decision was taken to use these facilities for educating and training students in disciplines new to Oman. Information Technology, Business and Tourism, Art and Design, and Communication Studies were identified as the key areas best suited to the economic and intellectual development of the country and thus five of the six Colleges of Education became Colleges of Applied Sciences (CAS) in 2005, specifically for the purpose of delivering these new degrees.

110 PACIFIC JOURNALISM REVIEW 17 (2) 2011 
Preparing intellectual property for these degrees was put out to international tender and won by the New Zealand Tertiary Education Consortium (NZTEC), consisting of Victoria University of Wellington, Waikato, Massey and Otago universities along with AUT University. The consortium also included Polytechnics International New Zealand (PINZ) and the Academic Colleges Group (ACG). Victoria University of Wellington was responsible for English language provision across the degrees while Otago University provided a Bachelor of Information Technology; the University of Waikato, a Bachelor of Business in Tourism; and AUT University, a Bachelor of Art and Design, and a Bachelor of Communication Studies (BCS). The AUT University BCS in general, and its Journalism major in particular, will be the focus of this discussion.

\section{General learning materials development}

The contract between the Ministry of Higher Education (MOHE) in Oman and NZTEC specified that the New Zealand universities would provide 'learning materials' which were defined as:

1. Lecture notes for all lectures and corresponding PowerPoint presentations;

2. For courses with weekly tutorials, corresponding tutorial sheets;

3. Assignments with corresponding marking guides; and

4. Exams with corresponding marking guides. (Services contract, 2006 - 2010, Schedule 1, Definitions and interpretation, p. 4).

This may have seemed a relatively straight-forward task to those negotiating the contract and may indeed have been comparatively simple in contentbased areas such as Information Technology and Business where systems and processes are likely to follow international standards and specifications. In Communication Studies, however, a complex interaction of culture, language (both visual and written), theory, intellectual freedom, creativity, imagination and personal opinion occurs.

Thus, in practice, there was no easy way to provide 'learning materials' in Communication Studies that would enable Omani students being taught in English to learn effectively. Although the view was expressed in New Zealand that these teaching materials should just 'be taken off the shelf', it quickly became apparent that this would not be possible and that much further contextualisation to Omani society would be required. Further change was 
necessitated by the English language capabilities of the students who had not been educated in English across all subjects prior to this point, but were now to be taught in a full English-language immersion style. Significantly, the students' IELTS scores were well below those required for entrance to university in New Zealand generally and to the BCS in particular. At AUT an IELTS score of 6.5 is required to enter the BCS: In Oman students were expected to graduate with an IELTS score of 5.5-6.

Furthermore, using English as the medium of instruction is itself a contested area. Education in English is perceived by some as providing access to an international language which will in turn offer more opportunities to graduates to continue their studies in English-speaking countries or to compete on a global employment stage. Others such as Al Shehri (2010) make the case that teaching in English or offering an English-based curriculum can be negative for local culture and prevent students from making the best of their education as they may well have done much better if they had been taught and assessed in Arabic. Proponents of development journalism, such as Papoutsaki (2007) who argues for de-colonising journalism curricula from western models and Robie (2008) who developed a Four Worlds news values model, would find fertile ground for extending their research in Oman and other Arab societies. And it is not just journalists and researchers who are concerned about the effects of introducing western concepts and attitudes into Arab societies; staff in the CAS privately expressed concerns about the wisdom of teaching Omani students to ask questions and think independently. For example, a senior staff member believed that an education which encouraged students to become critical of authority and the constraints of Omani public life was potentially dangerous (O'Rourke, 2011). The recent protests in Oman, including direct action at some of the CAS, may have proven him right.

Incorporating these and other intellectual and pedagogical challenges was difficult for both AUT and for the colleges in Oman. Staff at AUT were re-developing a degree programme that began in 1991 that was not only New Zealand's first Communication Studies degree, but arguably still the best Communication Studies degree in the country. The degree extends the popular Media Studies curriculum offered in secondary schools; is supported by the media industries and, as a recent quality assurance periodic review stated, is 'the university's flagship degree' (AUT, 2011). The situation for CAS staff was very different. Not only was there no existing Media Studies curriculum 
in Omani secondary education, there was no similar degree offered in Arabic which could provide advice to the emerging Communication programme. Moreover, the media industries in Oman are limited in scope, e.g. there is no coherent Public Relations industry and the broadcast media of television and radio are not included in the Omani degree, unlike the BCS where they have been majors since its inception. Furthermore, at the date of the last NZTEC moderation visit to Oman in June 2010, there was no functioning industry advisory committee and little in the way of contacts with industry leading to internships and work experience for students.

As well as the steep learning curve required by students, the staff in the Colleges of Education were now required to up-skill in business, IT, art and design, or communication, depending on the disciplines allocated to their new College of Applied Science. As a result, in the initial stages of the project, qualified staff, either from the relevant industries or from academia, were not available in Oman and, indeed, recruiting expatriates with appropriate experience quickly became an obstacle threatening the successful implementation of the degree. Once staff arrived in Oman and began to teach, staffing difficulties became more rather than less evident, with staff often being assigned to teach subjects outside their discipline area, teaching double or triple the normal 30 students in a tutorial and on some occasions, teaching papers out of sequence. This was especially true for Digital Media where sometimes the required software was not delivered in time or none of the current staff members could use the programme assigned to that particular paper.

Achieving the right level of resources was yet another difficulty for both staff and students. An overall list of all the books assigned by AUT to each paper in the programme was delivered to Oman very early in the projectMarch 2005 — but for budgetary and administrative purposes, books were only ordered up to six months prior to the papers being delivered. As books could only be sourced from within the Arab publishing zone, delays and censorship were common. On several QA trips to Oman, the NZTEC team saw prescribed texts under lock and key in the library, thus denying students access to them because the librarian considered the images offensive. In other cases, pages were ripped out and important information removed. Similarly, in resource rooms, the class sets of books were often not what AUT had recommended and core texts either remained on the shelves or were never purchased.

Obtaining appropriate resources and staffing were also issues at AUT 
where the re-development/writing team had no Arabic speakers nor anyone who had lived and worked in an Arab country; few experts in curriculum development; staff who were assigned to the project on the basis of their subject knowledge alone rather than interest or choice; and a gruelling schedule of deadlines in February and July extended over three years. This type of longterm, long-distance relationship was entirely new to the School of Communication Studies as was the experience of being responsible to not only internal channels within AUT but also to NZTEC as an academic entity outside the university. This hierarchical structure was overlaid again by links to the MOHE as the commissioning authority in Oman and by the functional academic and personal relationships which developed with the staff and students in Oman who were delivering, adjusting and, one hopes, benefitting from these learning materials. Thus, issues of language, communication expertise, teaching experience and style, motivation of redevelopers and the varying intellectual and social paradigms operating in Oman and New Zealand all formed part of the context in which this project was immersed.

\section{Structure of the Communication degree}

The Bachelor of Communication Studies (BCS) at AUT has eight majors: Advertising Creativity, Creative Industries, Digital Media, Journalism, Professional Communication, Public Relations, Radio and Television. But only five majors-Digital Media, International Communication, Journalism, Media Management and Public Relations-were chosen by the MOHE for the Bachelor of Applied Science in Communication in Oman. Of these five majors, three were based on the majors of the same name in the BCS and the other two-International Communication and Media Management-were developed specifically for Oman and broadly based on the Media Communication and Creative Industries curricula respectively.

Limitations on the material redeveloped for Oman included only offering three papers in each semester rather than the standard four per semester so that there was space in the degree plan for English language teaching, minors and/ or Arabic, and optional/elective papers. In addition, the degree was conceived as extending over a four-year period as opposed to the three years taken at AUT. Furthermore, the material offered within any major was confined to the core of the curriculum. Elective papers offered at AUT were not offered within the CAS, although this may change with further Omani curriculum 
development of the degree. Teaching staff in Oman would often check AUT's website and ask why the full range of electives or optional papers was being withheld from them. The answer was that the MOHE had chosen the minimum content required to obtain a degree. The original Memorandum of Understanding had included professional development courses in Oman run by AUT staff and reciprocal staff and student exchanges and secondments. None of these options has taken place because they were excluded from the final terms of the contract. During the crucial time of working out details and negotiating the final form of the contract, the Programme Director in Oman had not been appointed nor had his opposite number, the Programme Co-ordinator in New Zealand. Better induction processes and experience working with staff in both countries could have provided a clearer picture of where the programme was likely to run into difficulties and proactive rather than reactive processes and procedures could have been set in place

The most significant point of difference between AUT and the CAS, however, is that the degree is not conferred by AUT as a New Zealand degree but by the MOHE as an Omani degree. Thus the responsibility for curriculum change and re-development now belongs to Oman, and New Zealand no longer has any responsibility for quality assurance and moderation. This change in emphasis is clearly reflected in the name: The New Zealand Bachelor of Communication Studies was renamed as a Bachelor of Communications in Oman, then as a Bachelor of Applied Science in line with the name of the colleges but by the first graduation ceremony, had become an Omani Bachelor of Science. The ramifications of these and other issues will now be traced through comments on the journalism curriculum.

\section{Papers in the Omani journalism major}

Oman follows the pattern of the American and British education systems where the academic year begins in September, thus years of study are not complete within a single calendar year. A foundation year paper Introduction to Journalism and Public Relations is offered in Year 1, semester 2, followed by another seven papers in journalism, offered throughout the degree. In broad terms, the degree structure is based on a common core of papers in both the foundation year and Year 1 and then offers specialised journalism papers in Years 3 and 4 (see Table 1.)

Writing often and in multiple contexts is required to allow students the chance to develop and enhance writing skills, regardless of whether a process or 


\begin{tabular}{|c|c|c|}
\hline \multicolumn{2}{|c|}{$\begin{array}{l}\text { Bachelor of Science Degree structure } \\
\qquad 2005-2010\end{array}$} & \multirow[t]{2}{*}{ Journalism papers offered } \\
\hline 2006 & Year 1, Semester 1 (Foundation year) & \\
\hline 2007 & Year 1, Semester 2 & $\begin{array}{l}\text { Introduction to Public Relations and } \\
\text { Journalism }\end{array}$ \\
\hline & Year 2, Semester 3 & None \\
\hline 2008 & Year 2, Semester 4 & None \\
\hline & Year 3, Semester 5 & Journalism \\
\hline 2009 & Year 3, Semester 6 & None \\
\hline & Year 4, Semester 7 & $\begin{array}{l}\text { Public Affairs Reporting } \\
\text { Editing and Design } \\
\text { News Reporting }\end{array}$ \\
\hline 2010 & Year 4, Semester 8 & $\begin{array}{l}\text { New Media Journalism } \\
\text { Radio Journalism } \\
\text { Television Journalism }\end{array}$ \\
\hline
\end{tabular}

genre-based approach is used (Badger \& White, 2000; Cope \& Kalantsis, 1993; Elbow, 2008; Tribble, 1996). This recursive practice is even more important when students are writing in another language and/or are journalism students. However, there is no sequential development and little ongoing enhancement of journalistic writing skills as students have no journalism papers in second year at all and a further gap in Year 3 before a full three papers in each semester of Year 4 (see Table 1). This is a major flaw in the progression through the programme; one that could be profitably addressed in Oman.

\section{Specific Journalism papers and issues associated with redevelopment} At AUT, Journalism, along with Public Relations, is one of the two most popular majors. With close to 300 students in every cohort, and eight majors to support, entry is competitive and restricted to 45 high-achieving students. In Oman, because of the difficulties with English language, students are reluctant to choose Journalism because it is very difficult to write in English all day every day and also hard to question those who are considered superior to you. The 'flowery' and almost sycophantic prose that is standard in Oman's three daily papers in English (Times of Oman, Oman Observer and Muscat Daily) is very different from the fact-based way information is processed and published in New Zealand. AUT journalism staff were acutely aware as they were re-developing papers that 'translating' their content and approach 
to journalism then 'transposing' it into another country and culture was unlikely to succeed and had the capacity to fail on a large scale.

A range of issues including the perennial problems of contextualisation to Oman, providing sufficient Omani examples and concern for Islamic sensitivities were regularly encountered as work progressed on the Journalism major. In the early stages of this redevelopment, staff were not always mindful of their new and different audience, especially in terms of geography, personal names, street names and companies etc. The potential for causing cultural offence was ever present with the most striking cultural 'misfire' being the sentence originally used to illustrate the 'Who? What? Where? Why? When? How?' structure of journalistic writing: i.e.

Lady Godiva rode naked through the streets of Coventry.

Papers such as Public Affairs Reporting and News Reporting which are also deeply rooted in cultural institutions and traditions were probably the most difficult to contextualise and required a great deal of research and reference to Omani newspapers. Although theory was used to help students consider and develop their own ideas, having an opinion and being prepared to express that opinion in public and to one's superiors in society is not necessarily encouraged. Oman is a country which still has a royal court, where the Sultan goes on a mediaeval royal progress every year, and where the Sultan has absolute power, despite the existence of the Majlis al Shura as a semi-democratic parliament to advise him. Omanis are well able to dispute issues and to argue in private but pre-Arab Spring society demanded public compliance with the accepted conventions. Being required to think critically and analytically was thus a daunting task for students, one which resulted in plagiarism in many cases as students accepted the view of experts and appropriated their words. Such an environment means that the news reporting that is acceptable in New Zealand is not acceptable or in many cases, even possible in Oman. It should also be noted that staff in the CAS have now decided to teach referencing skills and have introduced SafeAssignment (anti-plagiarism software).

The more obviously media-based papers of Editing and Design, New Media Journalism, Radio Journalism and Television Journalism were popular with students, in part because of the technology involved but also because of the practice of using Omani examples and comparing them with international 
examples in Editing and Design in particular. The fact that these papers had demonstrable and practical yet creative outcomes also helped and all CAS are very proud of their student newspapers and magazines. These four papers also deal with growing convergence of the media and stress the need for students to be thoroughly familiar with each environment and to understand that writing for radio is different from writing for television and different again for writing on-line. Omani students are very familiar with television as all homes have satellite dishes and can access material from all around the world. This is part of the ongoing contradictions one finds in Omani society: Skype is forbidden but was used by staff and, in the early stages of the degree, broadband was not available but the population can access news and views from around the globe via satellite.

Other issues encountered in the redevelopment phase dealt with how to balance paying sufficient attention to the practical craft of journalism while also discussing academic and ethical concerns about the journalist's responsibilities and role in shaping public debate (NZTEC, 2008). Using Omani examples imaginatively as a basis for practical exercises in tutorials and using case studies also helped make material relevant to students (NZTEC, 2009).

Overall, significant re-consideration of approaches to the re-development task took place over the five years of the project, but the experience gained could have been even more valuable, had there been ongoing dialogue with Oman and provision within the terms of the contract for revision of papers to be done by CAS and AUT staff together. Working collaboratively from the earliest stages of the project could have allowed the more significant final year papers to be pitched at a more appropriate level in terms of student capabilities and competencies, as well as 'fit' with Oman society and approaches to journalism. Unfortunately, because of a number of circumstances within AUT, there was also little time for reflection within the journalism team until 2011.

\section{Staff reflections on preparing work for Oman}

A simple email survey was used to elicit journalism staff's opinions through the use of the following three headings:

1. The changes you had to make to teaching material and why you made them

2. The difficulties you encountered in preparing the work for Oman

3. Whether you think our style of Journalism would work in Oman (given what you have seen in Omani newspapers). 


\section{Figure 1: Original language and annotated suggestions for change}

\section{Original version}

The lecture series will focus on both the theoretical and practical sides to digital journalism, examining an array of issues that arise when news migrates to the web but also arming you with skills that will let you practise online journalism. Among the topics will be issues around new media, writing for the web, digital photography, design and navigation, citizen journalism, mobile journalism, surveillance societies, privacy and just what constitutes authentic journalism in today's world.

\section{Simplified version}

The lecture series will focus on both the theoretical and practical sides to digital journalism. (Shorter sentences are easier to understand.) We will examine (Making the language simple and direct also helps students understand) a range of issues ("array" changed to "range" as the vocabulary is more accessible) that arise when news migrates to the web and (stresses that the two things go together as opposed to "but" which highlights differences) we will also (replaced "arming you" with "teach" to make meaning clearer) teach you the skills that will let you practise online journalism.

We will discuss issues around: (The construction of this sentence was confusing so it is better to stick to a more straightforward style of writing again, for these particular students/audience)

- new media

- writing for the web

- digital photography

- design and navigation

- citizen journalism

- mobile journalism

- $\quad$ surveillance societies

- privacy and

- what constitutes authentic journalism in today's world.

(Bullet points help the students see all the separate points you are making. Long sentences containing many points are hard to understand. The list makes the divisions between points more obvious). 
Two of the six staff members involved did not complete the survey: one has left AUT and the other was overseas and unavailable when feedback was asked for. Some of the responses were short and of limited value while others showed real engagement with, and reflection on, the process of redeveloping material for another culture and society.

\section{Changes to teaching material}

Staff noted that there were a number of changes required that varied from paper to paper, above and beyond the main concerns of language suitability, contextualisation to Oman and cultural sensitivity to both Oman society and Islam.

Language suitability and the number and type of changes required were often extensive (see Figure 1) where the annotated simplified version also demonstrates the internal quality assurance work done within every paper by the Programme Coordinator.

Although the writer was working on their second Oman paper and was an experienced and successful senior journalist, the number and type of changes in language required for an English as a foreign language environment made the task of redeveloping papers very difficult and very time-consuming.

Contextualisation to Oman was an immense task, involving many hours of research trying to find Omani examples and taking great care not to offend Omani values. Figure 2 is an example of the work done for one tutorial exercise in order to make the material, interesting, accessible and relevant.

The lecturer commented that he did not want to use New Zealand examples and wanted to use examples that he had found in Omani newspapers and websites. This was made difficult by the lack of the news value 'conflict' in the few stories that appeared involving Government officials or Omani society where no controversy was allowed. Thus he was forced to use 'spot news', business and sport stories. 'For example, one of the exercises I set up for students in the "news selection" week required them to work in groups to discuss the stories available for that day's edition' (see Figure 2).

There were 15 weeks of teaching material for every one of the 47 papers involved in the Oman project as a whole. In the eight papers in the Journalism major, this equated to a total of 120 lectures and 120 tutorials to be redeveloped along with readings, exemplars, audio-visual support, assessments and examinations supported by appropriate marking guides. 


\section{Figure 2: Examples of stories sourced for use in one tutorial}

\section{New radio station}

A new Arabic radio station, Al Waisal, is going to air next week. It will play Omani and Arabic music, but have news on the hour. (Picture of the host in the studio.)

\section{Oil prices fall further}

An OPEC meeting has failed to reach agreement on further production cuts to stem the falling oil price. (Picture of OPEC leaders at meeting in Bahrain.)

\section{Trade with Japan}

Increased trade is likely after a week of trade talks between Japan and the Sulatnate of Oman. (Picture of His Highness Sayyid Haitham bin Tariq Al Said in discussion with Emperor Akihito of Japan in Tokyo.)

\section{Medical conference}

Over 400 medical specialists from six countries attended a three-day conference at the Oman Medical College. The conference ended yesterday. (Picture of Dr Ali bin Jaffer bin Mohammed opening the conference.)

\section{Concert today}

The Muscat Men's Chorus and the Muscat Christian Harmony (a 60-member choir) will perform at a concert at St Thomas in Ruwi tonight. (No picture.)

\section{Cricket result}

Carillion Alawi lost to Sur XI by 11 runs when the two cricket teams met at the OACII ground yesterday. One of the Carillion players was knocked unconscious when the ball hit him in the head. (Picture of the player being carried from the ground.)

\section{Air Force celebration}

A celebration was held yesterday at the headquarters of the Royal Airforce of Oman. This was to mark the completion of a course on aviation safety at the air base. (Picture of a certificate being presented.)

\section{Mobile phones in flight}

Emirates is to extend its trial of mobile phone services in its aircraft. Passengers on all Emirates flights will now be able to use their mobile phones. (Picture of Emirates Boeing 777-300.) 
Cultural sensitivity to both Omani society and Islam was an on-going and recurring problem. Although orientations were held for staff every semester and detailed briefing notes distributed, there were often glitches or problems in areas where staff were using examples that had worked well in New Zealand. The most outstanding of these continues to be the Digital Media exercise where a brief scenario was provided for a short film:

\section{Boy meets girl in bar}

It is difficult to imagine how five words could be more culturally offensive. When asked to alter this, the writer was genuinely perplexed as to what was wrong and could not see why it was altered to:

\section{Girl meets mother in café.}

The most common areas of difficulty with cultural sensitivity were images or photographs that included alcohol or advertising for alcohol as well as many other advertisements e.g. young men and women on dates or too close to each other; and references to Western popular culture, especially television programmes. For example, when images of strong women were required to illustrate a point in a lecture, the sexualised images of Desperate Housewives used in New Zealand were replaced by those from Grey's Anatomy where educated and strong, capable women were pictured in scrubs and on occasions, masks, for much of the show (O’Rourke \& Johnson, 2011).

In their emailed responses to the survey questions, staff also mentioned the problems of simplifying material, especially in final year papers, for the language level of the students; difficulties with particular tasks such as subbing and writing headlines; and the problem of knowing whether Omani staff would be experienced journalists or general teachers assigned to this area and thus how much explanation and detail would be required for staff as well as students.

Another lecturer worried that 'some lectures may well have seemed more relevant to Western ideologies of personal independence-say, the lecture on the surveillance society' and another staff member would have preferred to co-create the work by working directly with staff in the colleges in this area. Changes were also made to take culture into account; to be gender-neutral; and to simplify content as students would be coming to the Radio Journalism and Television Journalism papers without prior knowledge or experience in 
these areas, unlike BCS students in New Zealand who would have worked in both media earlier in their degree. Finally another senior journalist, while also acknowledging language and cultural issues such as the rights of women, stated: 'My biggest issue was trying to devise a paper that addressed such things as the public's right to know, privacy, human rights, press freedom etc. for a country that does not acknowledge such things as it is not a democracy.'

\section{Difficulties in preparing the work for Oman}

All journalism staff who worked on the project commented on not having sufficient time available for the task. The time allowance in the later stages of the project was 0.2 or one day a week and staff were able to work either in the office or at home, whichever suited them best. All staff were working from established and well-developed papers in New Zealand, but found that contextualising the material for Oman, using simple language at all levels of the programme and being culturally sensitive took far more time than expected. As they were also scouring Omani newspapers on-line for examples to use in both lectures and tutorials, the associated research was another time-consuming task. Working at weekends was common and although staggered deadlines for finishing the work were provided in the hopes of setting achievable goals, these were rarely met. The deadlines for completing all papers in the four years of the programme were always 1 February and 1 July. In the three or four weeks before the final deadline in July 2009, writing staff scrambled to catch up and complete the remaining lectures and tutorials on top of their other teaching and research commitments.

\section{The nature of journalism in Oman}

Journalism staff were in a unique position to comment on the process of developing teaching material for a very different culture, society and religion as they were the most exposed through newspapers to how that society presented itself and which concerns were publicly 'discussable'. All expressed doubt about the wisdom of teaching Western style journalism in Oman as the conditions of freedom of speech, democracy and critical analysis of society seemed to be absent, at least at the time (2006-2009) papers were being rewritten.

One writer contrasted the challenging role of Western media with the way in which Omani journalism seems to support the status quo. He argued that all details of the journalism in Oman are different, right down to how the intro is constructed for example, by referring and deferring to the Sultan. 
Perspicaciously, he also wrote: 'All that can be hoped for is that gradually as Omani society opens up, its journalism will be an integral part of that and reflect the process as well.' Another writer, who went searching for Omani examples to use in his paper, considered the lack of stories about political and social issues to be a reflection of the type of society Oman is.

The writer of the Television Journalism paper commented on production and technical values as being the same between New Zealand and Oman, but felt that objectivity could be missing in favour of positive messages about identity and supporting other Arab states, thus clearly linking Omani journalism to development journalism (Papoutsaki, 2007, 2008: Robie, 2006, 2008: Sharma, 2007). This was explicitly linked to Oman being a member of the Arab State Broadcasting Union (ASBU) which aims to create relationships and cooperation among broadcasting institutions for the explicit purpose of building Arab national identity. The writer felt that New Zealand television journalism is more like that of al Jazeera while noting that al Jazeera was criticised by the ASBU (to which it does not belong) because it '(does) not demonstrate a commitment to Arab media principles and show respect to the Arab League charter' (Miles, 2005, p. 47). How recent events in the uprisings across many Arab countries were reported may or may not have changed officially-sanctioned state journalism and public broadcasting of television and radio journalism but it will almost certainly have repercussions - both positive and negative, perhaps — on how journalism is taught in Omani statefunded higher education institutions.

QA visits to the colleges over a four-year period showed that, despite concerns about English language competence, subbing and writing headlines in particular, staff and students were enthusiastic about, and engaged well with, the Journalism major. Copies of Te Waha Nui (Communication Studies at AUT's award-winning student newspaper) were distributed in Oman and it is a shame that an ongoing partnership has not eventuated whereby students could submit articles to each others' newspapers. However, whether student newspapers still exist in Oman and whether their content, and the content of mainstream newspapers, has been significantly altered by the events of the Arab spring remains uncertain.

\section{Omani journalism and the Arab uprising}

In 2011, with the events of the Arab uprising in Tunisia, Egypt, Yemen, Libya, Bahrain and Syria following on from popular protests in Iran and 
the steady increase in citizen journalism throughout the Arab world, Omani newspapers and blogs have certainly dipped their toes into social and political activism. On 27 February, the BBC Middle East news site commented on the protests in Sohar and stated that two protesters had been killed, protests were taking place in Salalah and a small protest (300 people) had occurred in the capital city, Muscat. The Sultan moved quickly to make assurances that the living allowance for students would be increased and six government ministers were fired. A query to a colleague in Oman in late March provided information that twelve ministers had been sacked, protests were continuing and students in colleges across the country, including the CAS, were disrupting normal activities.

Over the time period from 27 February to 29 June 2011 much was written in Omani newspapers and blogs about the form that protests were taking and the way that the government was responding. A convenience sample of comments from Oman Observer, Times of Oman and Muscatdaily.com showed a number of common themes behind the writing as well as particular editorial policies being played out. For example, the Oman Observer was characterised by a complimentary stance towards the Sultan and the benefits that he had brought to the country rather than in-depth coverage of the protests; the Times of Oman, when reporting the protests after they were finished, did so with an emphasis on punishment for crime while Muscatdaily.com was prepared to deal with the reasons for the protests and criticise the government and protesters alike. Issues that were discussed varied between the online and print versions of newspapers with the print versions generally being more conservative and less inclined to criticise the government openly or the Sultan at all.

\section{Muscatdaily.com}

What do we want? (28 February) identifies the protesters' main demands as wanting an end to corruption and influence, more jobs, higher wages and lower prices for water and electricity, better healthcare and education; issues the writer seems to sympathise and identify with. Yet at the same time the comfortable politically correct rhetoric of the Sultan as saviour of the country and source of all goodness continues to be employed. This leads to a juggling act of praising the Sultan while criticising the governmenta pattern that can be seen in other journalism of the period, especially the al Lawati article of 12 March, We want accountability. Similar issues are identified as the protesters' main concerns; both writers dismiss illogical or 
personal aspects of the protesters' demands; both writers state that they are young and end the pieces by asking readers to support change. While the first writer stated that the list of protesters' concerns has been posted on every local Internet forum as well as in emails and SMS, social media's role in the uprising is more explicit throughout Reform and freedom of expression (13 March). Here the writer focuses on a controversial blogger's right to express an opinion and hopes that the government will not block the website as content will just surface elsewhere. In A new Oman (15 March) another writer comments that Facebook, internet forums, blogs, Twitter and YouTube have all remained unblocked and have been 'on fire'. Given that few Omani citizens read newspapers because they are so heavily censored, she finds this acceptance of comment as astonishing as the fact that peaceful protests have continued for three weeks-'Discovering that the government will tolerate our protests is unbelievable, but I suppose with recent events in the Middle East they have no other choice'.

\section{Oman Observer}

Samples from the Oman Observer on 5 March, 30 March and 4 April 2011 show more restraint than comments on Muscatdaily.com, possibly as censorship has long been a fact of life for print journalists in Oman. On 5 March the first two paragraphs of Oman's new dawn praised the Sultan as usual before moving to commenting on the events in Sohar in a bizarre paragraph, that seems to allow some legitimacy to the protesters; criticises the government in a roundabout way and blames the media-all at the same time. The 30 March 2011 article quotes many different citizens whose comments are curiously alike in generally blaming protesters and praising the Sultan. By 4 April, the focus was on reporting a meeting between the Deputy Prime Minister and the editors-in-chief of various newspapers in which reform was stressed, but protest actions were condemned; freedom of expression was acknowledged, but newspapers were urged to self-censor; and the value of Omani culture was seen to reside in the Sultan who was portrayed as the source of modernisation and a better life for all Omanis.

\section{Times of Oman}

Articles published in the Times of Oman on 23 April, 14 May and 29 June 2011 deal with a later stage of the unrest. In 3,000 march in Salalah, call end to corruption published two months (23 April) after the initial protests in Salalah, people including a local cleric, were brave enough to be quoted in 
the press by name and were reiterating old demands in the areas of government corruption, wages and jobs while still continuing to praise the Sultan and make a distinction between him and the government. Moreover, the article notes that 'Last week, His Majesty the Sultan pardoned 234 protesters arrested during disturbances', perhaps giving rise to a belief that protesting was now acceptable in Oman. Such a belief was decisively crushed in Security forces clear protest camps in Salalah and Muscat (14 May) where the Times reported security forces firing shots into the air, destroying protesters' tents and arresting hundreds in Salalah; the army using armoured vehicles and troops to disrupt protest in Sohar; and closing down the protesters' sit-in outside the Majlis al Shura in Muscat. By 29 June in Five-year jail term for seven in Sohar case all that was seemingly left to do was to report on punishments handed down by the courts.

\section{Conclusion}

While acknowledging that an analysis of the cultural-political forces at work during the Arab Spring are beyond the scope of this case study, comments made in articles in all three newspapers suggest some changes in journalism in Oman. Critiques of public policy and governmental practice within Oman were communicated through Twitter, YouTube, internet forums, blogs, Facebook, emails and mobile phones. Such criticisms seemed to be widespread and lasted far longer than would have been expected. 'Oman's "revolution" (the only possible word that can describe the situation) is all anyone talks about these days.' (Muscatdaily.com, 15 March). While it is unlikely that changes in the political climate throughout the Middle East will have an immediate effect on the journalism curriculum taught in the CAS, journalists and journalism educators may find themselves agreeing with Muscatdaily. com's young woman writer's statement that:

As a young Omani woman, I don't know how to react to these changes or what to think. In fact, I don't think anyone knows really. The only thing I know for sure is that Oman will never be the same again, and it sure is exciting to be here to witness it!

(15 March, 2011) 


\section{References}

Al Bandary, M. S. (2005). Meeting the challenges: The development of quality assurance in Oman's Colleges of Education. Higher Education, 50, 181-195. DOI 10.1007/s10734-004-6348-y.

AUT University. (2011) PARC Programme Review Report: Bachelor of Communication Studies. Auckland, New Zealand: Author.

BBC World news. Retrieved on 6 April 2011, from www.bbc.co.uk/news/worldmiddle-east- 12590588

Badger, R., \& White, G. (2000). A process genre approach to teaching writing. ELT Journal 54/2 April 2000. Oxford: Oxford University Press. Retrieved on 21 August, 2011 from http://203.72.145.166/ELT/files/54-2-6.pdf.

Cass, P. (2011). 'Teacher! Teacher! I want “A”, teacher!' Pacific Journalism Review, 17(2); pp 130-147 [in press].

Central Intelligence Agency. The CIA World Factbook. Retrieved on 16 August 2011, from www.cia.gov/library/publications/the-world-factbook/geos/mu.html

Cope, B., \& Kalantzis, M. (Eds.) (1993). The powers of literacy: A genre approach to teaching writing. Pittsburgh, PA: University of Pittsburgh Press.

Cultural office of the embassy of Oman in Washington, DC. Retrieved on 17 August 2011, from www.omani.info/education.htm

Elbow, P. (2008). Writing without teachers. (2nd ed.). USA: Oxford University Press.

Miles, H. (2005). Al-Jazeera: The inside story of the Arab news channel that is challenging the West. New York, NY: Grove Press.

Muscat Daily. (2011 February 28; March 12; March 13; and April 4) Retrieved on 1 June 2011, from www.muscatdaily.com/Archive/Stories-Files/What-do-we-want

New Zealand Tertiary Education Consortium and Ministry of Higher Education, Oman (NZTEC/MOHE). (2005). Services contract between New Zealand Tertiary Education Consortium Ltd and AUT University. Oman Ministry of Higher Education, Colleges of Applied Science degree procurement project, 2006-2010. Oman/New Zealand.

NZTEC (2008). Evaluation of course report: Journalism. Wellington, New Zealand: NZTEC.

NZTEC (2009). Evaluation of course report: Editing \& Design. Wellington, New Zealand: NZTEC.

Oman Observer (2011 March 5, March 30 and April 4). Retrieved on 1 June 2011, from http://main.omanobserver.om/node/42693

O'Rourke, S. (2011). Curriculum development for Oman 2006 to 2011: Implications for offshore education and challenges for intercultural communication within New Zealand. Communication Journal of New Zealand/He Kohinga Korero.12(1), 42-56.

O'Rourke, S., \& al-Bulushi, H. A. (2010). Managing quality from a distance: A case study of collaboration between Oman and New Zealand. Quality in Higher Education, 16(3), 197-201. 
O'Rourke, S., \& Johnson, R. (2011). Internationalising a media studies degree in Arab higher education: A case study arising from an agreement between New Zealand and Oman. In T. Sabry (Ed.) Arab cultural studies: Mapping the field. London, UK: IB Tauris.

Papoutsaki, E. (2007). Decolonising journalism curricula: A research and 'development' perspective. Media Asia, 34(2), pp. 71-87.

Papoutsaki, E. (2008). The need for local research approaches: De-westernising research methodologies for higher education curricula in developing countries. In H. Vessuri \& U. Teichler (Eds.). Universities as Centres for Research: An Endangered Species? UNESCO/Sense: Rotterdam.

Robie, D. (2006). 'Four worlds' news values: Media in transition in the South Pacific. Australian Journalism Review 28(1), pp. 71-88.

Robie, D. (2008). Media and development in the Pacific: Reporting the why, how and what now? In S. Singh \& B. Prasad (Eds.) Media and development issues and challenges in the Pacific Islands (pp. 11-26). Fiji Institute of Applied Studies and Pacific Media Centre, Lautoka, Fiji and Auckland.

Sharma, D. C. (2007). Development journalism: An introduction. Manila, Philippines: Ateneo de Manila University.

Times of Oman (2011, April 23; May 14 and June 29). Retrieved on 1 June 2011, from www.timesofoman.com/searchdetail.asp?cat $=\&$ detail $=43676 \&$ rand $=\mathrm{hXiD}$ PQUrANTpCAjKYolpDPI64X

The World Health Organisation. Oman: Trade in health-related services and GATS. Retrieved on 16 August 2011, from http://gis.emro.who.int/HealthSystemObservatory/PDF/Trade And Health Services/Oman.pdf

Tribble, C. (1996). Writing. Oxford: Oxford University Press.

Susan O'Rourke is head of undergraduate programmes in the School of Communication Studies at AUT University. She is programme leader for the Bachelor of Communication Studies and a research associate of the Pacific Media Centre. She was also the programme coordinator for the Oman project. She has co-authored books on business communication and her research interests include quality assurance in higher education, intercultural communication, curriculum development and teaching writing.

Susan.Orourke@aut.ac.nz 